\title{
Transfection of the Helicobacter pylori CagA gene alters MUC5AC expression in human gastric cancer cells
}

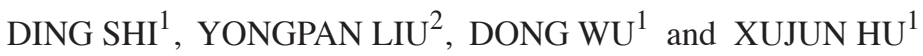 \\ ${ }^{1}$ Department of Gastroenterology, Ningbo No. 2 Hospital, Ningbo, Zhejiang 315000; \\ ${ }^{2}$ Department of Gastroenterology, First People's Hospital of Yuhang District, Hangzhou, Zhejiang 311100, P.R. China
}

Received May 10, 2016; Accepted August 24, 2017

DOI: 10.3892/ol.2018.7960

\begin{abstract}
Helicobacter pylori, the primary causative agent of stomach cancer, is known to affect gastric mucin expression. However, the underlying molecular mechanisms mediating this $H$. pylori-dependent effect remain unknown. In the present study, the effect of exogenous expression of the $H$. pylori virulence factor, CagA, on mucin $5 \mathrm{AC}$ oligomeric muscus/gel-forming (MUC5AC) expression was investigated using an in vitro model of the gastric mucosa. AGS cells were either untreated or transfected by a vector control (pCDNA3.1) or heterologous DNA, which induced CagA overexpression (pCDNA3.1-CagA). The expression and functionality of MUC5AC was analyzed using the reverse transcription-quantitative polymerase chain reaction and immunofluorescence assays. The expression of $H$. pylori-CagA in AGS cells was able to significantly upregulate MUC5AC expression compared to the vector control. In addition, immunofluorescence assays were able to validate increased MUC5AC expression following exogenous expression of $H$. pylori-CagA. The results of the present study revealed that the $H$. pylori-derived virulence factor CagA was able to increase the expression of MUC5AC. As this mucin constitutes an important ecological niche for $H$. pylori, this response may be involved in H.pylori colonization of the stomach.
\end{abstract}

Correspondence to: Dr Xujun Hu or Dr Ding Shi, Department of Gastroenterology, Ningbo No. 2 Hospital, 41 Northwest Street, Ningbo, Zhejiang 315000, P.R. China

E-mail: huxujun@tom.com

E-mail: shidingyuhang@163.com

Abbreviations: PVDF, polyvinylidene difluoride; CK, control group; pCDNA3.1-CagA, CagA overexpression group; pCDNA3.1, empty plasmid group

Key words: mucin 5AC oligomeric muscus/gel-forming, Helicobacter pylori, cytotoxin-associated gene A, stomach

\section{Introduction}

Mucin 5AC oligomeric muscus/gel-forming (MUC5AC) is a principal component of the gastric mucosa $(1,2)$ and constitutes an important part of the ecological niche, where the stomach bacterium Helicobacter pylori is located (3). Adhesion to the gastric mucosa is important in the life cycle of $H$. pylori (4). As MUC5AC is an important receptor for gastric mucosa adhesion (5-7), efficient colonization of the stomach requires high expression of MUC5AC by gastric epithelial cells $(8,9)$. Previous studies have demonstrated that the stomach epithelium reacts to $H$. pylori infection by activating pro-inflammatory signaling pathways (10), thereby activating innate defense mechanisms against $H$. pylori, which may include the downregulation of MUC5AC expression in the human gastric mucosa $(2,6,11,12)$. Downregulation of MUC5AC expression in the gastric mucosa is evident following $H$. pylori-associated transformation of the gastric epithelium into cancer (13-15). As MUC5AC expression is key for the ecological niche required for $H$. pylori $(6,7)$, it is to be expected that, in response to evolutionary pressure, the bacterium may have evolved compensatory mechanisms to combat the downregulation of MUC5AC. However, to date, such mechanisms have been incompletely characterized.

The association between $H$. pylori infection and gastric epithelial MUC5AC expression is well-recognized $(6-9,16)$, there are a limited number of studies regarding the molecular mechanisms that mediate $H$. pylori-dependent compensatory responses, with respect to host downregulation of MUC5AC mucin gene expression. The downregulation of MUC5AC expression appears to be derived from an epithelial reaction towards the urease virulence factor of H.pylori (17). Therefore, it may be hypothesized that other virulence factors may mediate compensatory responses. In view of the importance of $H$.pylori for gastric oncological transformation and its involvement in a number of types of non-malignant disease (18), the identification of virulence factors potentially involved is required. Of these virulence factors, cytotoxin-associated gene A (CagA) has been associated with the interaction and modification of cellular phenotype and intracellular signaling pathways e.g., CagA induction of tumor suppressor gene hypermethylation via AKT-NFKB pathway in gastric cancer development, and is likely to mediate these effects (19-21).

The aforementioned considerations prompted the present study to investigate the interaction between $H$. pylori-derived 
CagA and MUC5AC expression in the gastric epithelium. It has already been established that upon CagA injection into the gastric epithelial cytosol by the bacteria, a number of cellular responses facilitating bacterial propagation and pathological responses are initiated (22-24). Therefore, CagA expression may affect MUC5A expression. It has been well established that CagA is injected directly from the bacteria into the gastric epithelial cytosol through its needle-like structure (23). In the present study, to isolate the effects of CagA from other $H$.pylori-induced molecules, in particular the urease virulence factor, a CagA expression construct was created that allows the cell-autonomous introduction of the bacterial protein into gastric epithelial cells. The results of the present study indicated that $\mathrm{Cag} \mathrm{A}$ is able to drive MUC5AC expression in gastric epithelial cells. Therefore, CagA insertion into host cells by $H$. pylori may constitute a bacterial defense mechanism against host downregulation of MUC5AC.

\section{Materials and methods}

Cell lines and cell culture. The AGS gastric adenocarcinoma cell line was purchased from the Shanghai Cell Bank (Shanghai, China). AGS cells were cultured in Ham's F-12 medium supplemented with $10 \%$ fetal bovine serum and were maintained at $37^{\circ} \mathrm{C}$ in an atmosphere containing $5 \% \mathrm{CO}_{2}$ (all Gibco; Thermo Fisher Scientific, Inc., Waltham, MA, USA) (25).

Transfection of the CagA gene. Control group (CK), empty-plasmid group (pCDNA3.1) and overexpression CagA group (pCDNA3.1-CagA) were set up. The vector used for expressing CagA protein was the pcDNA 3.1 plasmid from Life Technologies (Thermo Fisher Scientific, Inc.). The CagA-coding insert was established by total gene synthesis. For transfection, $4 \mu \mathrm{g}$ CagA plasmid and $6 \mu \mathrm{l}$ Lipofectamine ${ }^{\circledR} 2000$ (Invitrogen; Thermo Fisher Scientific, Inc.) were added to $200 \mu 1 \mathrm{~F} 12$ medium. Following mixing and incubated at room temperature for $20 \mathrm{~min}$, the mixture was added to AGS cells that had been plated and had reached $75 \%$ cell confluence.

Reverse transcription-quantitative polymerase chain reaction (RT-qPCR) for CagA, GAPDH and MUC5AC expression in the AGS model of the gastric epithelium. The AGS cells were harvested and RNA was extracted with RNaEXTM Total RNA Isolation Solution (Generay Biotech Co., Ltd., Shanghai, China). Total RNA $(1 \mu \mathrm{g})$ was mixed with $2 \mu 1$ reagent $5 \mathrm{X}$ Prime Script RT Master mix (Vazyme Biotech Co., Ltd., Nanjing, China) and $\mathrm{RNase}$ Free $\mathrm{dH}_{2} \mathrm{O}$ up to $10 \mu \mathrm{l}$, prior to being reverse transcribed in a one-step process at $50^{\circ} \mathrm{C}$ for $15 \mathrm{~min}$ and the introduction of inactivated enzymes at $85^{\circ} \mathrm{C}$ for $5 \mathrm{sec}$, each for once cycle according to the manufacturer's protocols. The cDNA product is finally stored at $-80^{\circ} \mathrm{C}$. The mRNA levels of MUC5AC of all groups were assessed using qPCR. The forward and reverse primer sequences used for determining H. pylori-CagA expression were 5'-ATTCACAATAACGCT CTG-3' and 5'-ACCACCTGCTATGACTAA-3', respectively. The forward and reverse primer sequences for establishing Homo GAPDH (Gene ID, 2597; product size, 258 bp) expression were 5'-AGAAGGCTGGGGCTCATTTG-3' and 5'-AGG
GGCCATCCACAGTCTTC-3', respectively. The forward and reverse primer sequences for determining Homo MUC5AC (Gene ID, 4586; product size, 281 bp) expression were 5'-ACG GGAAGCAATACACGG-3' and 5'-GGTCTGGGCGATGAT GAA-3', respectively. For the qPCR amplification reaction, $10 \mu$ l IQ SYBR-Green Supermix (Tiangen Biotech Co., Ltd., Beijing, China) was used in conjunction with $1 \mu \mathrm{l}$ cDNA product, $1 \mu \mathrm{l}$ forward primer $(10 \mu \mathrm{M}), 1 \mu \mathrm{l}$ reverse primer $(10 \mu \mathrm{M})$ and $8 \mu \mathrm{l}$ water. The thermocycling conditions used were as follows: $50.0^{\circ} \mathrm{C}$ for $3 \mathrm{~min}, 95.0^{\circ} \mathrm{C}$ for $15 \mathrm{~min}$, followed by 40 cycled of $95.0^{\circ} \mathrm{C}$ for $10 \mathrm{sec}, 59^{\circ} \mathrm{C}$ for $25 \mathrm{sec}$ and $72^{\circ} \mathrm{C}$ for $25 \mathrm{sec}$. Quantification was performed using the $2^{-\Delta \Delta \mathrm{Cq}}$ method (26).

Verification of CagA expression at the protein level. The protein expression of the CagA transgene in AGS cells was validated using western blot analysis. Total protein was extracted from non-transfected AGS cells, vector control-transfected AGS cells and AGS cells transfected with CagA-encoding plasmid. The cells were lysed by protein extraction buffer (Beyotime Institute of Biotechnology, Haimen, China) and the protein concentration was determined by the BCA method. The CagA levels were assessed by adding $30 \mu \mathrm{g}$ of protein per lane, electrophoresis using a $10 \%$ polyacrylamide gel, followed by transfer to a polyvinylidene difluoride (PVDF) membrane. The PVDF membrane was subsequently blocked with a solution containing 5\% skimmed milk powder and $5 \%$ bovine serum albumin (BSA (Shanghai Biyuntian Bio-Technology Co., Ltd.) for $1 \mathrm{~h}$ at room temperature, followed by washing and the addition of the CagA antibody (catalog no. sc-25766; Santa Cruz Biotechnology, Inc., Dallas, TX, USA) at $4^{\circ} \mathrm{C}$ overnight. Following washing three times with Tris-buffered saline containing Tween-20 for $15 \mathrm{~min}$, the PVDF membrane was exposed to the goat anti-rabbit IgG $(\mathrm{H}+\mathrm{L})$ Highly Cross-Adsorbed Secondary Antibody (catalog no. A16113; Invitrogen; Thermo Fisher Scientific, Inc.) and incubated for $1 \mathrm{~h}$ at room temperature, followed by repeated washing. Subsequently, the membrane was visualized using BeyoECL Plus (Shanghai Biyuntian Bio-Technology Co., Ltd.), according to the manufacturer's protocol and routine procedures using a gel imaging analyzer (Chemidoc XRS+; Bio-Rad Laboratories, Inc., Hercules, CA, USA).

Immunofluorescent analysis of MUC5AC expression. The protein levels of MUC5AC of all groups were assessed using fluorescence. Cells ( $3 \times 10^{4}$ per well) exposed to the appropriate transfections and conditions were grown for $24 \mathrm{~h}$ in 24 -well plates under routine conditions, washed three times with PBS and fixed with a $4 \%$ paraformaldehyde solution for $15 \mathrm{~min}$ at $37^{\circ} \mathrm{C}$. Subsequently, the samples were washed with PBS twice for 5 min and permeabilized using a 10 -min incubation with $0.1 \%$ Triton X-100 in PBS. Following two washes for 5 min with PBS, non-specific immunoreactivity was blocked via a 90-min incubation with $1 \% \mathrm{BSA}$ in $0.3 \mathrm{M}$ glycine at $37^{\circ} \mathrm{C}$ (plates were sealed). Subsequently, MUC5AC antibody (catalog no. sc-398985, dilution 1:100; Santa Cruz Biotechnology, Inc.) was added and the samples were incubated overnight at $4^{\circ} \mathrm{C}$. The following day, the fluorescence-labeled (Alexa Fluor ${ }^{\circledR} 555$ ) Alexa Fluor $^{\circledR}$ 555 goat anti-mouse IgG (H+L) antibody (catalog no. A21424; 
Table I. CagA mRNA levels in CK, pCDNA3.1 and pCDNA3.1-CagA groups.

\begin{tabular}{lc}
\hline Group & $\begin{array}{c}\text { mRNA expression level } \\
\text { (mean } \pm \text { standard deviation; } n=3)\end{array}$ \\
\hline CK & $0.00 \pm 0.00$ \\
pCDNA3.1 & $0.00 \pm 0.00$ \\
pCDNA3.1-CagA & $491.11 \pm 0.41$ \\
\hline
\end{tabular}

CagA, cytotoxin-associated gene A; CK, control group; pCDNA3.1, empty-plasmid; pCDNA3.1-CagA, CagA expression plasmid.

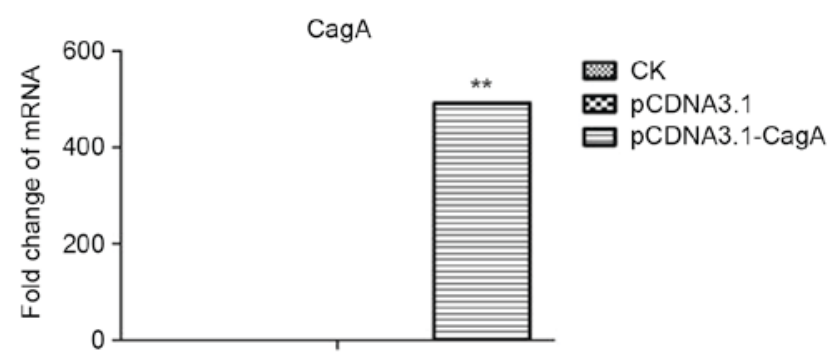

Figure 1. CagA expression levels in CK, pCDNA3.1 and pCDNA3.1-CagA groups as determined using reverse transcription-quantitative polymerase chain reaction. mRNA for CagA was not detected in the CK group or the pCDNA3.1 group. The level of CagA expression was significantly increased compared with $\mathrm{CK}$ and pCDNA3.1 groups. pCDNA3.1-CagA group vs. pCDNA3.1 group ( $\left.{ }^{*} \mathrm{P}<0.01\right)$; pCDNA3.1-CagA group vs. the $\mathrm{CK}$ group $\left({ }^{* *} \mathrm{P}<0.01\right)$. CagA, cytotoxin-associated gene A; CK, control group; pCDNA3.1, empty plasmid; pCDNA3.1-CagA, CagA expression plasmid.

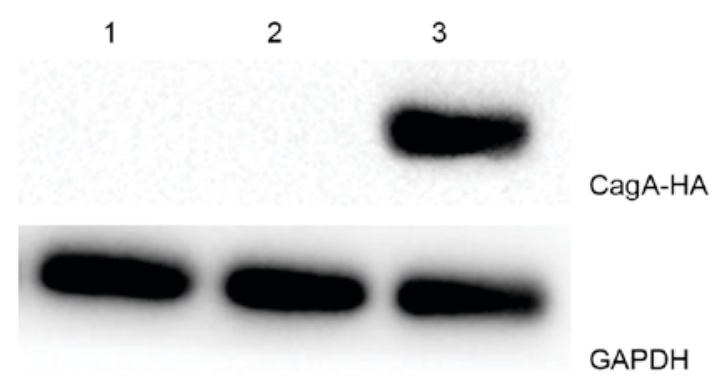

Figure 2. CagA expression levels of all groups as detected by western blotting. CagA protein was detected in the pCDNA3.1-CagA group and was not detected in the $\mathrm{CK}$ group or the pCDNA3.1 group. 1, control group; 2, pCDNA3.1 group (empty plasmid); 3, CagA expression plasmid; CagA, cytotoxin-associated gene.

dilution 1:800; Invitrogen; Thermo Fisher Scientific, Inc.) was added, and the experimental samples were incubated under humidified conditions for $1 \mathrm{~h}$ at $37^{\circ} \mathrm{C}$. For staining of nuclei, 4',6-diamidino-2-phenylindole was added, and the samples were incubated for $10 \mathrm{~min}$. Subsequently, the samples were washed three times with PBS for 5 min and mounted on glass slides and analyzed using magnification, $\mathrm{x} 200$ fluorescence microscopy (IX73; Olympus Corporation, Tokyo, Japan), to assess the subcellular distribution of MUCAC immunoreactivity.

Statistical analysis. The RT-qPCR results of CagA and MUC5AC expression in AGS cells were statistically analyzed
Table II. MUC5AC mRNA levels in CK, pCDNA3.1 and pCDNA3.1-CagA groups.

\begin{tabular}{lc}
\hline Group & $\begin{array}{c}\text { mRNA expression level } \\
\text { (mean } \pm \text { standard deviation; } \mathrm{n}=3 \text { ) }\end{array}$ \\
\hline CK & $1.00 \pm 0.12$ \\
pCDNA3.1 & $1.29 \pm 0.06$ \\
pCDNA3.1-CagA & $1.87 \pm 0.07$ \\
\hline
\end{tabular}

MUC5AC, mucin 5AC oligomeric muscus/gel-forming; CK, control group; pCDNA3.1, empty-plasmid; pCDNA3.1-CagA, CagA expression plasmid.

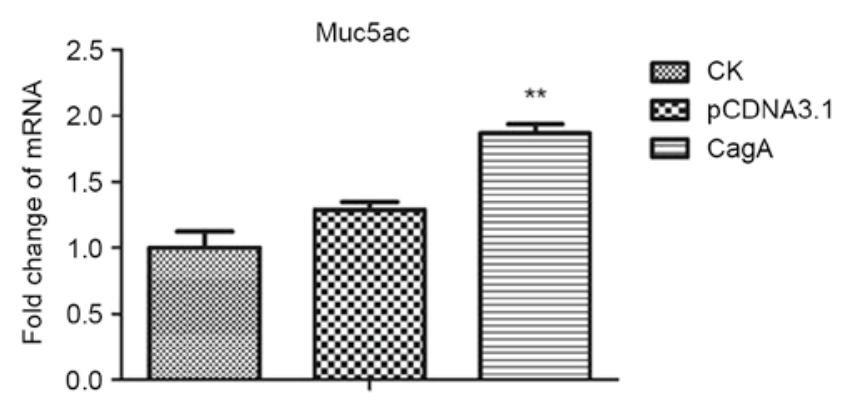

Figure 3. Levels of MUC5AC expression in CK, pCDNA3.1 and pCDNA3.1-CagA groups as determined using reverse transcription-quantitative polymerase chain reaction. The level of MUC5AC expression in the pCDNA3.1-CagA group was significantly increased compared with the pCDNA3.1 and CK groups. pCDNA3.1-CagA group vs. pCDNA3.1 group ( $\left.{ }^{* *} \mathrm{P}<0.01\right)$; pCDNA3.1-CagA group vs. the CK group $\left({ }^{* *} \mathrm{P}<0.01\right)$. MUC5AC, mucin 5AC oligomeric muscus/gel-forming; CagA, cytotoxin-associated gene A; CK, control group; pCDNA3.1, empty-plasmid; pCDNA3.1-CagA, CagA expression plasmid.

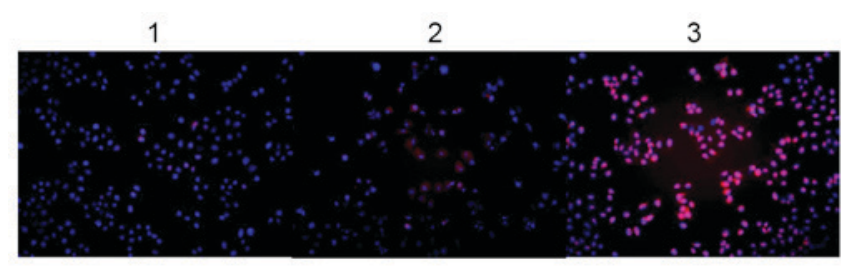

Figure 4. MUC5AC expression status of CK, pCDNA3.1 and pCDNA3.1-CagA groups as determined using immunofluorescence assays. The pCDNA3.1-CagA group revealed markedly more intense MUC5AC protein staining, compared with the CK and pCDNA3.1 groups. 1, CK (control group); 2, pCDNA3.1 group (empty plasmid); 3, CagA expression plasmid; MUC5AC, mucin 5AC oligomeric muscus/gel-forming; CagA, cytotoxin-associated gene A.

and calculated using the CFX Manager PCR analysis software (version 3.0; Bio-Rad Laboratories, Inc.). Following densitometric analysis using Image $\mathbf{J}$ software (National Institutes of Health, Bethesda, MD, USA), the CagA protein levels, determined using western blot analysis, were established. The data were subsequently analyzed using the Student's t-test or by one-way analysis of variance test for selected data pairs, following by the Tukey post-hoc test. $\mathrm{P}<0.05$ was considered to indicate a statistically significant difference. The experiments were repeated 3 times. 


\section{Results}

Exogenous expression of CagA in an experimental model of gastric epithelium. To investigate the effects of exogenous CagA expression in the gastric epithelium, AGS cells were transduced with a CagA-expressing plasmid, and the results were compared with cells transduced with an empty vector or non-transduced cells. This strategy successfully established heterologous CagA expression at the RNA level. The level of CagA expression in all groups as detected by RT-qPCR are shown in Table I and Fig. 1. The level of CagA expression in the pCDNA3.1-CagA group was significantly increased compared with the pCDNA3.1 group and the untreated AGS cells group $(\mathrm{P}<0.01, \mathrm{P}<0.01$; Fig. 1). In addition, at the protein level, the induction of exogenous CagA expression was successful. Western blots of all experimental groups are shown in Fig. 2, and CagA protein was only detected in the pCDNA3.1-CagA group. Therefore, this experimental set-up enabled the present study to analyze the effect of exogenous CagA expression on the levels of MUC5AC in AGS cells.

CagA expression upregulates MUC5AC. AGS cultures transduced with CagA were analyzed for MUC5AC expression using RT-qPCR and compared with the appropriate controls. As evident from the results presented in Table II and Fig. 3, heterologous CagA expression increased MUC5AC expression at the RNA level, compared with the control group. The level of MUC5AC expression in the pCDNA3.1-CagA group was significantly increased compared with that of the pCDNA3.1 and $\mathrm{CK}$ groups $(\mathrm{P}<0.01, \mathrm{P}<0.01$, respectively). As presented in Fig. 4, this result was validated using immunofluorescence assays, demonstrating substantial upregulation of MUC5AC, following the transfection of AGS cells with the CagA expression plasmid, compared with the control. Therefore, the results of the present study demonstrated that CagA was able to increase MUC5AC expression.

\section{Discussion}

At present, it is typically accepted that the gastric epithelium reacts to $H$. pylori infection by downregulating MUC5AC $(2,6,11-15)$. This may be a protective response towards $H$. pylori, which enables the removal of this organism from its ecological niche. However, the precise interaction between $H$. pylori and MUC5AC remains unclear. The gastric epithelial downregulation of MUC5AC may involve bacterial urease, as evident from experiments involving AGS gastric cancer cells that were infected with the UreB-isogenic mutant of $H$. pylori (17). It is speculated that evolutionary pressure has favored the emergence of $H$. pylori variants that may counteract this effect. In the present study, it was demonstrated that the CagA virulence factor may exhibit a function in this process. The results of the present study revealed that the expression of MUC5AC, determined using RT-qPCR and immunofluorescence assays, was significantly upregulated upon the introduction of cellular CagA. Therefore, the injection of CagA into the gastric epithelial cytosol by $H$. pylori represents a countermeasure of $H$. pylori against gastric epithelial defensive downregulation of the MUC5AC glycoprotein in response to bacterial infection.
MUC5AC has been demonstrated to co-localize with $H$.pylori and functions as an important $H$.pylori receptor, which tethers $H$. pylori to the gastric mucosa $(5,6)$. Therefore, it may be hypothesized that $H$.pylori aims at creating a favorable environment by stimulating gastric epithelial MUC5AC production, which facilitates bacterial adherence. In this sense, injection of CagA into gastric epithelial cells may stimulate these cells to produce MUC5AC early in the infection process, causing a transient increase in MUC5AC expression that facilitates additional colonization (27). A subsequent interaction between the bacterium and gastric cells leads to morphological alterations in the cell and the injury of host-cell epithelial barrier that is associated with $H$. pylori infection (28). MUC5AC is only produced by the stomach surface epithelium (29), which is consistent with this cell type being the important target for $H$. pylori during the infection process (30). These findings indicated that CagA has a role as a MUC5AC-targeting bacterial effector. The molecular mechanisms underlying how the virulence factor may result in transactivation of the MUC5AC promotor remain unknown. However, mucin production is typically a protective response against bacterial infection, and therefore, it may be exploited by the CagA protein (31-33). MUC5AC, as a principal component of the mucosal layer, protects the stomach surface from chemical, enzymatic, mechanical and microbial challenge, and its upregulation constitutes an intuitive response of the epithelium to infection (1,2,7,11,29,34-36). Additional studies are required to delineate the molecular mechanisms, which mediate the effects of CagA on MUC5AC transcription. However, the results of the present study have revealed that CagA is sufficient for cell-autonomous upregulation of MUC5AC and have therefore, to the best of our knowledge, revealed a novel mechanism employed by this bacterium for its colonization of the stomach.

\section{References}

1. Ho SB, Takamura K, Anway R, Shekels LL, Toribara NW and Ota $\mathrm{H}$ : The adherent gastric mucous layer is composed of alternating layers of MUC5AC and MUC6 mucin proteins. Dig Dis Sci 49: 1598-1606, 2004.

2. Byrd JC, Yunker CK, Xu QS, Sternberg LR and Bresalier RS: Inhibition of gastric mucin synthesis by Helicobacter pylori. Gastroenterology 118: 1072-1079, 2000.

3. Hunt RH, Camilleri M, Crowe SE, El-Omar EM, Fox JG, Kuipers EJ, Malfertheiner P, McColl KE, Pritchard DM, Rugge M, et al: The stomach in health and disease. Gut 64: 1650-1668, 2015.

4. Allen A, Newton J, Oliver L, Jordan N, Strugala V, Pearson JP and Dettmar PW: Mucus and H. pylori. J Physiol Pharmacol 48: 297-305, 1997.

5. van den Brink GR, Hardwick JC, Tytgat GN, Brink MA, Ten Kate FJ, Van Deventer SJ and Peppelenbosch MP: Sonic hedgehog regulates gastric gland morphogenesis in man and mouse. Gastroenterology 121: 317-328, 2001.

6. Van de Bovenkamp JH, Mahdavi J, Korteland-Van Male AM, Büller HA, Einerhand AW, Borén T and Dekker J: The MUC5AC glycoprotein is the primary receptor for Helicobacter pylori in the human stomach. Helicobacter 8: 521-532, 2003.

7. Kocer B, Ulas M, Ustundag Y, Erdogan S, Karabeyoglu M, Yldrm O, Unal B, Cengiz O and Soran A: A confirmatory report for the close interaction of Helicobacter pylori with gastric epithelial MUC5AC expression. J Clin Gastroenterol 38: 496-502, 2004.

8. Lindén SK, Wickström C, Lindell G, Gilshenan K and Carlstedt I: Four modes of adhesion are used during Helicobacter pylori binding to human mucins in the oral and gastric niches. Helicobacter 13: 81-93, 2008 
9. Magalhães A and Reis CA: Helicobacter pylori adhesion to gastric epithelial cells is mediated by glycan receptors. Braz J Med Biol Res 43: 611-618, 2010.

10. van Den Brink GR, ten Kate FJ, Ponsioen CY, Rive MM, Tytgat GN, van Deventer SJ and Peppelenbosch MP: Expression and activation of NF-kappa B in the antrum of the human stomach. J Immunol 164: 3353-3359, 2000.

11. Kang HM, Kim N, Park YS, Hwang JH, Kim JW, Jeong SH, Lee DH, Lee HS, Jung HC and Song IS: Effects of Helicobacter pylori Infection on gastric mucin expression. J Clin Gastroenterol 42: 29-35, 2008.

12. Shi D, Qiu XM and Bao YF: Effects of Helicobacter pylori infection on MUC5AC protein expression in gastric cancer. Future Oncol 9: 115-120, 2013.

13. Shi D, Qiu XM and Yan XJ: The changes in MUC5AC expression in gastric cancer before and after Helicobacter pylori eradication. Clin Res Hepatol Gastroenterol 38: 235-240, 2014.

14. Wang RQ and Fang DC: Effects of Helicobacter pylori infection on mucin expression in gastric carcinoma and pericancerous tissues. J Gastroenterol Hepatol 21: 425-431, 2006.

15. Matsuda K, Yamauchi K, Matsumoto T, Sano K, Yamaoka Y and Ota H: Quantitative analysis of the effect of Helicobacter pylori on the expressions of SOX2, CDX2, MUC2, MUC5AC, MUC6, TFF1, TFF2 and TFF3 mRNAs in human gastric carcinoma cells. Scand J Gastroenterol 43: 25-33, 2008.

16. Morgenstern S, Koren R, Moss SF, Fraser G, Okon E and Niv Y: Does Helicobacter pylori affect gastric mucin expression? Relationship between gastric antral mucin expression and $H$. pylori colonization. Eur J Gastroenterol Hepatol 13: 19-23, 2001.

17. Perrais M, Rousseaux C, Ducourouble MP, Courcol R, Vincent $P$, Jonckheere N and Van Seuningen I: Helicobacter pylori urease and flagellin alter mucin gene expression in human gastric cancer cells. Gastric Cancer 17: 235-246, 2014.

18. McLean MH and El-Omar EM: Genetics of gastric cancer. Nat Rev Gastroenterol Hepatol 11: 664-674, 2014.

19. Zhang BG, Hu L, Zang MD, Wang HX, Zhao W, Li JF, Su LP, Shao Z, Zhao X, Zhu ZG, et al: Helicobacter pylori CagA induces tumor suppressor gene hypermethylation by upregulating DNMT1 via AKT-NFKB pathway in gastric cancer development. Oncotarget 7: 9788-9800, 2016.

20. Figura N, Marano L, Moretti E and Ponzetto A: Helicobacter pylori infection and gastric carcinoma: Not all the strains and patients are alike. World J Gastrointest Oncol 8: 40-54, 2016.

21. Tohidpour A: CagA-mediated pathogenesis of Helicobacter pylori. Microb Pathog 93: 44-55, 2016.

22. Handa O, Naito Y and Yoshikawa T: CagA protein of Helicobacter pylori: A hijacker of gastric epithelial cell signaling. Biochem Pharmacol 73: 1697-1702, 2007.

23. Tanaka H, Yoshida M and Azuma T: The role of CagA in H.pylori infection. Nihon Rinsho 67: 2245-2249, 2009 (In Japanese).
24. Stein M, Ruggiero P, Rappuoli R and Bagnoli F: Helicobacter pylori CagA: From pathogenic mechanisms to its use as an anti-cancer vaccine. Front Immunol 4: 328, 2013.

25. Perrais M, Pigny P, Buisine MP, Porchet N, Aubert JP and Van Seuningen-Lempire I: Aberrant expression of human mucin gene MUC5B in gastric carcinoma and cancer cells. Identification and regulation of a distal promoter. J Biol Chem 276: 15386-15396, 2001.

26. Livak KJ and Schmittgen TD: Analysis of relative gene expression data using real-time quantitative PCR and the 2(-Delta Delta C(T)) method. Methods 25: 402-408, 2001.

27. Hayashi T, Senda M, Morohashi H, Higashi H, Horio M, Kashiba Y, Nagase L, Sasaya D, Shimizu T, Venugopalan N, et al: Tertiary structure-function analysis reveals the pathogenic signaling potentiation mechanism of Helicobacter pylori oncogenic effector CagA. Cell Host Microbe 12: 20-33, 2012.

28. Wu J, Xu S and Zhu Y: Helicobacter pylori CagA: A critical destroyer of the gastric epithelial barrier. Dig Dis Sci 58: 1830-1837, 2013.

29. Nordman H, Davies JR, Lindell G, de Bolós C, Real F and Carlstedt I: Gastric MUC5AC and MUC6 are large oligomeric mucins that differ in size, glycosylation and tissue distribution. Biochem J 364: 191-200, 2002.

30. Hatakeyama M: Oncogenic mechanisms of the Helicobacter pylori CagA protein. Nat Rev Cancer 4: 688-694, 2004.

31. Fukuda M, Kawakubo M, Ito Y, Kobayashi M, Lee H and Nakayama J: Assay of human gastric mucin as a natural antibiotic against Helicobacter pylori. Methods Enzymol 415: 164-179, 2006.

32. Kawakubo M, Ito Y, Okimura Y, Kobayashi M, Sakura K, Kasama S, Fukuda MN, Fukuda $M$ and Katsuyama T: Natural antibiotic function of a human gastric mucin against Helicobacter pylori infection. Science 305: 1003-1006, 2004.

33. Kobayashi M, Lee H, Nakayama J and Fukuda M: Roles of gastric mucin-type $\mathrm{O}$-glycans in the pathogenesis of Helicobacter pylori infection. Glycobiology 19: 453-461, 2009.

34. Ota H, Nakayama J, Shimizu T, Nakayama J, Graham DY and Katsuyama T: Relation of $\mathrm{H}$ pyroli to gastric mucins and gastric surface mucous gel layer. Gut 48: 869-871, 2001.

35. Tanaka S, Mizuno M, Maga T, Yoshinaga F, Tomoda J, Nasu J, Okada H, Yokota K, Oguma K, Shiratori Y and Tsuji T: H. pylori decreases gastric mucin synthesis via inhibition of galactosyltransferase. Hepatogastroenterology 50: 1739-1742, 2003.

36. Jia Y, Persson C, Hou L, Zheng Z, Yeager M, Lissowska J, Chanock SJ, Chow WH and Ye W: A comprehensive analysis of common genetic variation in MUC1, MUC5AC, MUC6 genes and risk of stomach cancer. Cancer Causes Control 21: 313-321, 2010. 